\title{
LUXEMBURGER FAMILIENNAMENBUCH
}

\section{LUXEMBURGER FAMILIENNAMEN- BUCH}

Erstmals werden in dieser Publikation die Familiennamen des heutigen Luxemburgs aus sprachhistorischer Perspektive analysiert und systematisiert. Die 2500 häufigsten Familiennamen werden basierend auf synchronen und diachronen Quellen sorgfältig hinsichtlich Namentyp, Etymologie, sprachhistorischer Entwicklung und geographischer Verbreitung untersucht. Die Beschreibung der Verbreitung ist nicht auf Luxemburg eingeschränkt, sondern berücksichtigt auch die Grenzregionen mit Deutschland, Frankreich, Belgien und den Niederlanden, um historische Gemeinsamkeiten und Migrationen im Raum zwischen Maas und Rhein herauszustellen. Berücksichtigung findet folglich auch der Sprachkontakt zwischen Germania und Romania. Durch ein Verweissystem werden strukturell zusammengehörige Namen (etwa Varianten, Zusammensetzungen oder Ableitungen) miteinander verbunden, sodass die Charakteristiken der Luxemburger Familiennamenlandschaft deutlich wird. Eine ausführliche Einleitung sowie mehrere Anhänge runden dieses Nachschlagewerk ab.

- Nachschlagewerk für 2500 Familiennamen des heutigen Luxemburg

- Beschreibung der geographischen Verbreitung auch in den Grenzregionen mit Deutschland, Frankreich, Belgien und den Niederlanden

Cristian Kollmann, Peter Gillesund Claire Muller, Universität Luxemburg.

\section{XI, 407 Seiten, 30}

\section{Gebunden:}

Ladenpreis * $€[D] 59.95$

UVP *US\$ $84.00 / *$ GBP 44.99

ISBN 978-3-11-041060-O

eBook:

Ladenpreis *€ [D] 59.95

UVP *US\$ 84.00 / *GBP 44.99

PDF ISBN 978-3-11-041076-1

EPUB ISBN 978-3-11-041085-3

\section{Print/eBook:}

Ladenpreis * $€[D] 89.95$

UVP *US\$126.00/*GBP 67.98

ISBN 978-3-11-041077-8

Erscheinungsdatum: Januar 2016

Sprache der Publikation: Deutsch Fachgebiete:

Europäische Sprachen - Lateinisch und romanische Sprachen • Französisch

Europäische Sprachen • Germanische Sprachen - Deutsch

Theorien und Fachgebiete

Namenforschung

Theorien und Fachgebiete - Kontrastive Linguistik

Zielgruppe: Sprachwissenschaftler, Onomastiker/Etymologen, Genealogen, interessierte Nichtfachleute, Institute, Bibliotheken. 